\title{
Determining the optimal number of yard trucks in smaller container terminals
}

\author{
Maja Stojakovic ${ }^{*}$ (D) and Elen Twrdy
}

\begin{abstract}
Background: In 2017, smaller container ports handled approximately 22\% of total containerized cargo. Nowadays liner operators are calling on those ports with larger ships and demanding fast and efficient turnaround of the ships in port. This is possible only if the berth has the right capacities, is working properly and achieves a good productivity level.

Methodology: Productivity level does not depend only on the quay crane capacities but also the transfer mechanisation, of which the main function is to serve quay cranes on one side and yard cranes on the other side. Choosing the correct type and number of vehicles to transfer container units from berth to yard has become a very important decision in every container terminal.

Results: In small container terminals yard trucks represents the most common type of transfer mechanization. That is why this research is based on the allocation of the right number of yard trucks to quay cranes in order to assure better productivity levels in the berth and yard subsystems. For this purpose, a discrete-event simulation modelling approach is used. The approach is applied to a hypothetical small container terminal, which includes operations on the berth-yard-berth relation.
\end{abstract}

Keywords: Container terminals, Yard tracks, Berth productivity, Operational efficiency

\section{Introduction}

A seaport container terminal is a transit point for containerized goods between sea vessels and land transportation modes, such as truck and trains [26]. Although seaport container terminals differ considerably in size, function, and geometric layout, they principally consist of the same subsystems [19]. These are the berth, yard and gate subsystems [2, 17]. The coordination among the three subsystems, the assignment of handling resources to the necessary activities and the scheduling of the different movement tasks are the main aspects to be managed and optimized in a seaport container terminal [26]. In container terminals, there are three types of handling equipment involved in the loading/discharging process: quay cranes-QCs, transfer mechanisation

* Correspondence: maja.stojakovic@fpp.uni-lj.si

University of Ljubljana, Faculty of Maritime Studies and Transport, Pot pomorščakov 4, Portorož, Slovenia

\section{Springer Open}

(c) The Author(s). 2021 Open Access This article is licensed under a Creative Commons Attribution 4.0 International License which permits use, sharing, adaptation, distribution and reproduction in any medium or format, as long as you give appropriate credit to the original author(s) and the source, provide a link to the Creative Commons licence, and indicate if changes were made. The images or other third party material in this article are included in the article's Creative Commons licence, unless indicated otherwise in a credit line to the material. If material is not included in the article's Creative Commons licence and your intended use is not permitted by statutory regulation or exceeds the permitted use, you will need to obtain permission directly from the copyright holder. To view a copy of this licence, visit http://creativecommons.org/licenses/by/4.0/. 
mechanisation is crucial. A very commonly used type of equipment in small ports and the most common one in the small northern Adriatic (NA) ports are YTs. YTs are manned vehicles that pull chassis carrying the containers. They represent a technologically modest means of container transport, as they are unable to lift containers - thus a crane is required for loading and unloading operations. This means that if there is not a good synchronization between QCs and YTs and between YTs and YCs, congestion can occur. The problem of smaller container terminals is that, on the one hand, they have space problems and, on the other, they have already established workflows for container handling. It is therefore financially more advantageous for a container terminal already in operation to purchase additional YTs than to restructure the terminal and purchase handling equipment of a different type. According to $\mathrm{He}$ et al. [14], the efficiency of container terminals depends to a large extent on the effectiveness of the allocation of terminal resources in the various phases of container handling.

However, according to Meisel [24] YTs are economically attractive and can provide high flexibility regarding the workload of a terminal. In our research, simulation processes will therefore be based on different numbers of YTs serving QCs. The scope of this research is to define the correct number of YTs that will reduce the turnaround time of the ship in a small container port. To achieve that, numerous computer simulations using Flexsim CT 3.3 software were performed on a hypothetical container terminal (CT). During the simulations, terminal characteristics like berth length, number of QCs, and type of ship were changed (Table 2) in order to gradually increase the annual traffic and capacity from 630,000 TEU to approximately 1 million TEU and evaluate how such an increase of traffic would influence the productivity of the berth in the first place and of the yard in the second place.

Since our research was not focused on a specific port, we combined the elements of various small size ports with similar properties. The basic criteria for the simulation terminal layout were represented by the NA ports of Koper, Trieste, and Rijeka, from which the most common factors were taken. The largest share of data was obtained from the port of Koper.

We note that there is a knowledge gap in the literature when we try to define the type and number of transfer mechanization for transferring container units from berth to yard in small CTs. The research is based on allocating the right number of YTs to the QCs to ensure better productivity levels in the berth and yard subsystems. We develop a model for berthyard operation with emphasis on proper allocation of transfer mechanization. The objective was to provide optimal berth function and thus faster transfer of the vessel in the port. The developed model is easy to use and allows a quick identification of the required mechanization in relation to the capacity of the CT.

The structure of the paper is as follows. Section 2 provides a literature overview, Section 3 provides the development of the methodology with four subsections explaining the framework and characteristics of the basic hypothetical CT, followed by the analysis of the basic model and the further methodology of the simulations performed to determine the optimal number of YTs in a small CT. The simulation results can be found in Section 4, while Section 5 provides a discussion and conclusion with the suggestion for further research.

\section{Literature overview}

Nowadays it is extremely important that a ship leaves the port as soon as possible, which means that high efficiency is required from the CT. This is usually measured in terms of operational productivity; such as ship turnaround time or yard utilization. According to Gharehgozli et al. [10] it is important to enable efficient work processes on the sea side, but that the yard stacking system also has a significant impact on the overall capacity of the terminal. The right choice of transfer mechanisation between the sea and land sides of the terminal, therefore, plays a very important role. In this context, a lot of research has been done in recent years on the use of YTs, as they have achieved great efficiency when properly planned [36].

\subsection{Terminal operating system (TOS) and terminal planning}

The basis for further research on container terminal operation systems was provided in the early 2000s by Steenken et al. [33], Stahlbock and Voß [32], Vis and De Koster [37] and Kim and Günther [19]. Later Böse [5], published a handbook of terminal planning, while Singgih et al. [30] have proposed a TOS design that includes integrated scheduling and various decision-making modules related to different aspects of operations in a new conceptual rail-based CT. Kourounioti et al. [21], on the other hand, focused on the container dwell time in the terminals. In 2019 Hervás-Peralta et al. [15], were the first to use the AHP (Analytic Hierarchy Process) to identify and hierarchize the TOS functionalities. A special role in measuring the efficiency of TOS in CTs is also played by the KPIs, which are decisive for the planning and further optimization of the CTs. An interesting study was conducted in this respect by Hinkka et al. [16], who analysed the indicators required for terminal planning and compared them with existing KPIs to measure the performance of ports and terminals. 
Although CT problems are related to each other, authors often address the specific issues of an individual segment of the terminal. That is why below some interesting studies on berth and storage productivity - reflecting interrelationships in ports - that pertain to our research are presented.

\subsection{Berth productivity}

The berth subsystem represents the most important part of the CT; since all subsequent processes in other subsystems of the terminals are connected to it. The arrival of ever larger container ships has led to a reduction in berth productivity, which is reflected in longer ship times in the port and higher costs for the ship operator. Seyedalizadeh Ganji et al. [29] pointed out that the length of time that the ship waits for berth availability and the ship's handling time are considered to be the most important measures of effectiveness for a $\mathrm{CT}$, so reducing each of these times enhances the productivity of the terminal. Most researchers therefore have focused on the optimal berth allocation problem (BAP) and the quay crane assignment problem (QCAP) by using generic algorithms $[3,4,11,18,23]$.

An important factor that affects ship handling time is QC productivity. This is measured by the number of moves per hour. Bartošek and Marek [1] pointed out that terminals are able to achieve maximum productivity to $80 \%$ of the computed number, due to productivity losses caused by operational disturbances. QC efficiency and impact on possible bottlenecks has been explained in detail by Goodchild and Daganzo [12]. Beškovnik et al. [2] also investigated QC productivity and its influence on berth utilisation. For this purpose, a comparison model of twenty selected global CTs was used to compare productivity in the process of subsystem productivity analysis. However, the productivity of QCs largely depends also on the type and number of the horizontal handling equipment used; this can be allocated to a specific QC or to more QCs simultaneously. The types and operational characteristics of the horizontal equipment were analysed by Carlo et al. [8]. In the classification according to the size of the ship, QCs are divided into several categories. In this study two of those categories are used [1]:

- Panamax QC - able to serve Panamax ships, 11-13 containers wide (rows).

- Post-Panamax QC - able to serve Post Panamax ships, 17-19 containers wide.

Our aim is to select the number of YTs so that despite the disorder in the storage area the QCs are able to achieve 20 moves/hour (Panamax QC) and 25 moves/ hour (Post-Panamax QC), respectively.

\subsection{Storage problems}

In the issued works that discuss storage problems most of the researchers are focused on optimizing transhipment operations and improving the utilization of storage space. An insight into the area's current research, as well as the precise description of the yard layout and the transhipment operations there, was provided by Carlo et al. [7]. Zhang et al. [40] and Woo and Kim [38] dealt with the problem of allocating storage space for containers, focusing mainly on the allocation of storage space to export containers. On the other hand, Zhao and Goodchild [42] analysed the impact of transfer mechanization on the transhipment effects of the terminal.

\subsection{Computer simulations}

Sometimes it is easier and more feasible to use built-in simulation programmes like ARENA software, MicroPort, AnyLogic, FlexSim CT, etc., that enables the detailed simulation of one terminal subsystem or the interoperability of two subsystems. A detailed review of the available research literature on the application of simulation models in port development over the last 54 years (1961-2015) was presented by Dragović et al. [9].

Sislioglu et al. [31] used Data envelopment analysis (DEA) in combination with ARENA software to develop a DST (decision support tool), the aim of which is to find the optimum investment to improve the CT productivity. They focused on minimizing the average turnaround time of the ship in the port while maximizing the container throughput. The same software has also been used by Kotachi et al. [20] who have modelled generic port operations to study how various different inputs can influence the outputs that include throughput, resource utilization and waiting times. AnyLogic software was used by Yang et al. [39] to create a simulation model of the AGV transport system that would effectively increase the utilization rate of QCs and YCs and reduce the time to task completion. On the other hand, Gamal Abd El-Nasser A. Said and El-Horbaty [27], have chosen FlexSim CT software to optimize solutions for the storage space allocation problem, taking into account all various interrelated CT handling activities. The proposed approach is applied on a real case study data of CT at Alexandria port. Stojaković and Twrdy [35] have used FlexSim CT software to determine how a different number of YTs assigned to a single QC can affect the productivity of that crane and the productivity of the entire berth subsystem in a small CT. In this study we chose to take a step forward and build a hypothetical CT in FlexSim CT software and monitor only the 


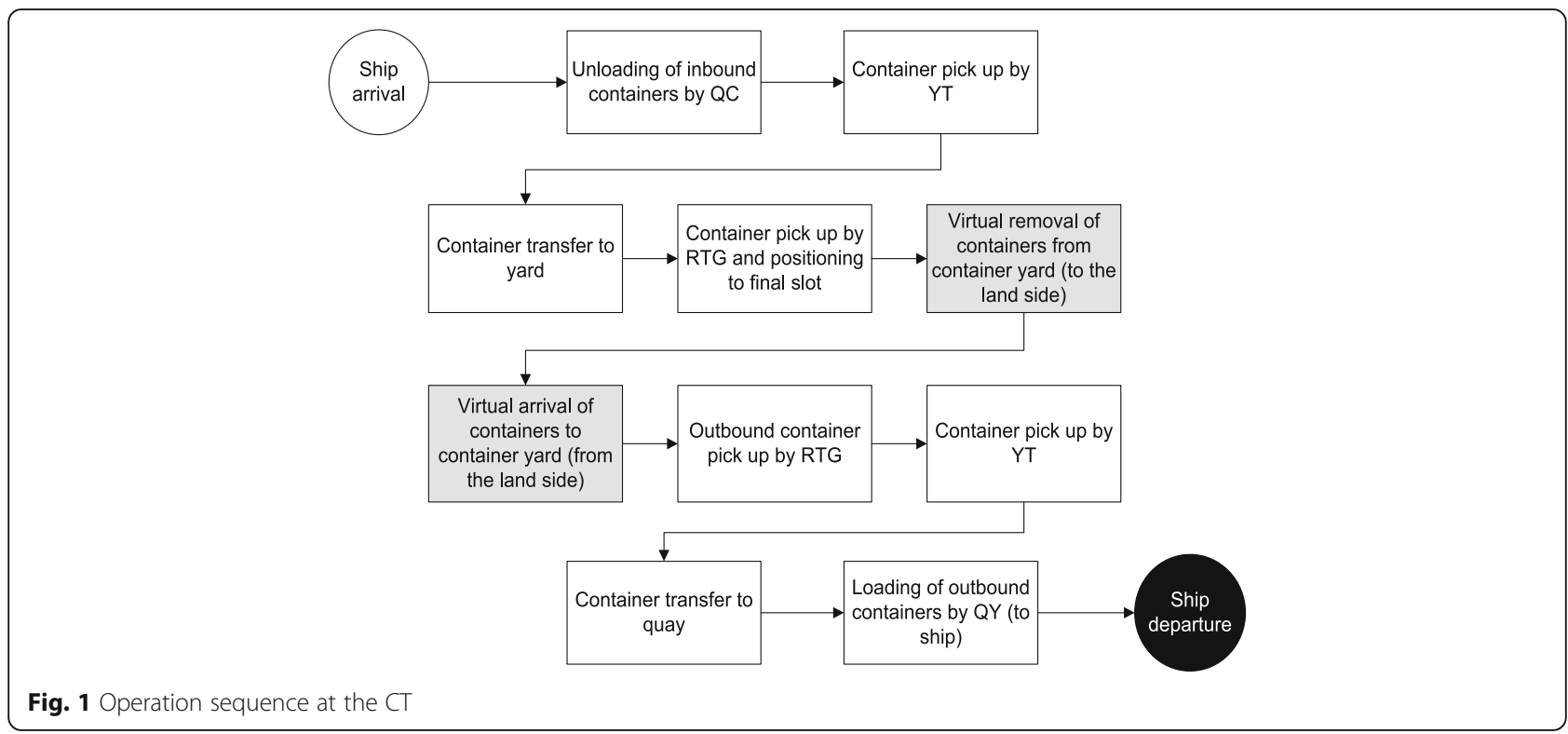

interrelations of the berth and yard subsystems, focusing primarily on the berth productivity by coordinating the number of YTs. In that way it was possible to obtain original data on the necessary number of YTs per QC according to the volume of annual throughput in order to achieve maximum productivity at the berth and thus the more rapid departure of large ships.

\section{Methodology development}

The methodology can be divided into four main steps:

- Presentation of the Framework. In the first step the framework of the simulations is presented. That section explains which data have been selected and included in the simulation software to build a basic CT simulation model. Furthermore, it contains the sequence of all the operations performed during the simulation.

- Terminal layout. After explaining the framework of the simulations, a terminal layout of the basic CT model is presented. In this step the physical characteristics that have been chosen to build the CT (berth and yard subsystems) are provided. As the performed simulations are based on real port data, the ship arrival schedule that has been used in the simulation is given.

\section{- Analyses of the simulation performed on the} basic $C T$. In the third step the results that were obtained with the simulation of the basic CT model are provided and discussed. The results have shown that YTs were crucial for the achievement of higher berth productivity and they also have significantly influenced the yard operations. Those findings therefore formed the basis for further simulations that enable us to determine the optimal number of YTs at the terminal of smaller sizes.

- Simulation running. The final step explains how the simulations have been run. To be able to determine the optimal number of YTs for a small $\mathrm{CT}$ the simulations were performed in three sets with a different number of YTs per QC. In each set seven different scenarios have been performed, changing several terminal characteristics and increasing the annual throughput of the CT up to 1 million TEU.

\subsection{Framework}

For the purpose of this research, a hypothetical CT, which is a Discrete Event Simulation (DES) model based on real data from the ports of Koper, Rijeka and Trieste, was built with the software FlexSim CT. FlexSim CT is a powerful "what-if" analysis tool used to model systems that change their state at discrete times as a result of specific events. Our research is based on the models developed by Gamal Abd El-Nasser A. Said and ElHorbaty [27] and Gamal Abd El-Nasser A. Said et al. [28]. Therefore, stochastic, dynamic and discrete problems were addressed in this simulation study.

The performed simulation covers all the berth-yardberth operations. The model was entered with all actual data regarding the containers that arrived at the terminal with the ship (import) and the data about the containers

Table 1 The basic CT model

\begin{tabular}{lll}
\hline & Quay & QC \\
\hline Berth 1 & $250 \mathrm{~m}$ & 4 Panamax (P) \\
Berth 2 & $350 \mathrm{~m}$ & 4 Post Panamax (PP) \\
\hline
\end{tabular}




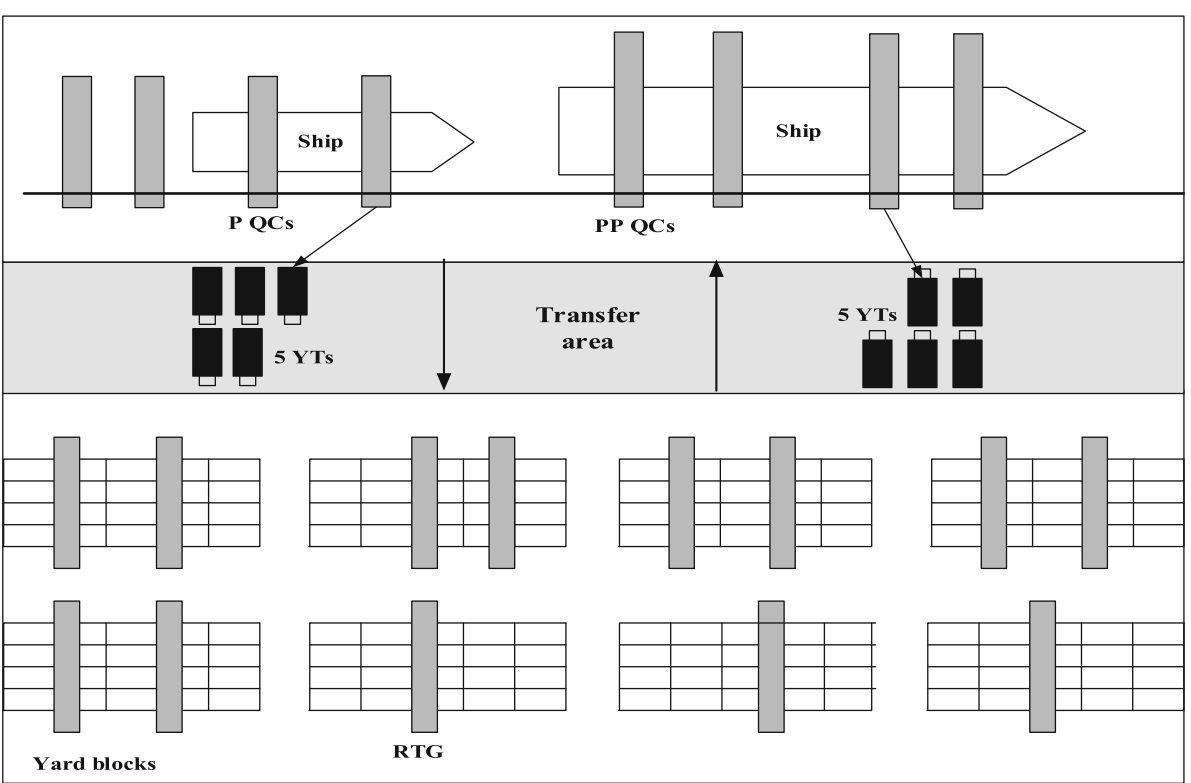

Fig. 2 Basic terminal layout

that had to be loaded on the ship to leave the port (export), while the number of containers entering and exiting the terminal by land has been performed virtually (by the software) according to the input parameters. All the simulations included the ship arrival at the terminal, the unloading of the inbound containers, container transfer to yard and their positioning in the final slot and vice versa. The sequence of the performed operations in the CT is shown in the Fig. 1.

For vessel simulation a real vessel arrival schedule has been used in which each ship service has a fixed planned arrival time that is the same each week, making realistic simulations possible (the window is shown in Fig. 3). The data regarding the transfer area, storage capacities and yard equipment were taken from the available data of the selected ports and combined for the purpose of the research.

\subsection{Terminal layout (input data)}

The basic simulation model was entered with the following input data: berth length, QCs, ships, incoming and outgoing containers, YTs, yard area, and YC.

The basic CT model captures one continuous quay of $600 \mathrm{~m}$ divided into two berths (Table 1, Fig. 2). In that way, the large vessels may occupy more than one berth, while small vessels may share a berth.

All QCs perform single cycling operations, which is usual in medium-sized and smaller ports. Transfer operations between the sea and storage area are done by YTs. Initially 5 YTs are assigned to every QC, meaning that $40 \mathrm{YTs}$ are placed at the terminal. The capacities of the variables changed during the seven scenario simulations are presented in Table 2.

The yard area has a storage capacity of 20,160 TEU and is placed parallel to the quay. It is divided into three

Table 2 Performed scenarios

\begin{tabular}{|c|c|}
\hline $\begin{array}{l}\text { Scenario sequence } \\
\text { number }\end{array}$ & Scenario description \\
\hline SCENARIO 1 & Basic model with $630,000 \mathrm{TEU}$ of annual throughput. \\
\hline SCENARIO 2 & $\begin{array}{l}\text { The quay of the basic model was extended by } 100 \mathrm{~m} \text { and ships were served by } 6 \text { PP and } 2 \text { P QCs. The annual throughput } \\
\text { remained unchanged. }\end{array}$ \\
\hline SCENARIO 3 & To the previous model a weekly service with a PP ship was added. The annual throughput rose to 689,000 TEU. \\
\hline SCENARIO 4 & $\begin{array}{l}\text { Another weekly service with a PP ship was added to the previous model, while one feeder service was eliminated. The } \\
\text { annual throughput changed to } 768,000 \text { TEU. }\end{array}$ \\
\hline SCENARIO 5 & $\begin{array}{l}\text { The QC layout was changed to } 7 \text { PP and } 1 \text { P. The ship schedule changed with one new PP service instead of a small one. } \\
\text { The annual throughput rose to } 844,000 \text { TEU. }\end{array}$ \\
\hline SCENARIO 6 & The weekly schedule changed with the purpose of increasing the annual throughput to 899,000 TEU. \\
\hline SCENARIO 7 & $\begin{array}{l}\text { In the last scenario only PP QCs were placed on the quay. The weekly schedule changed in order to increase the annual } \\
\text { throughput to } 990,000 \text { TEU. }\end{array}$ \\
\hline
\end{tabular}




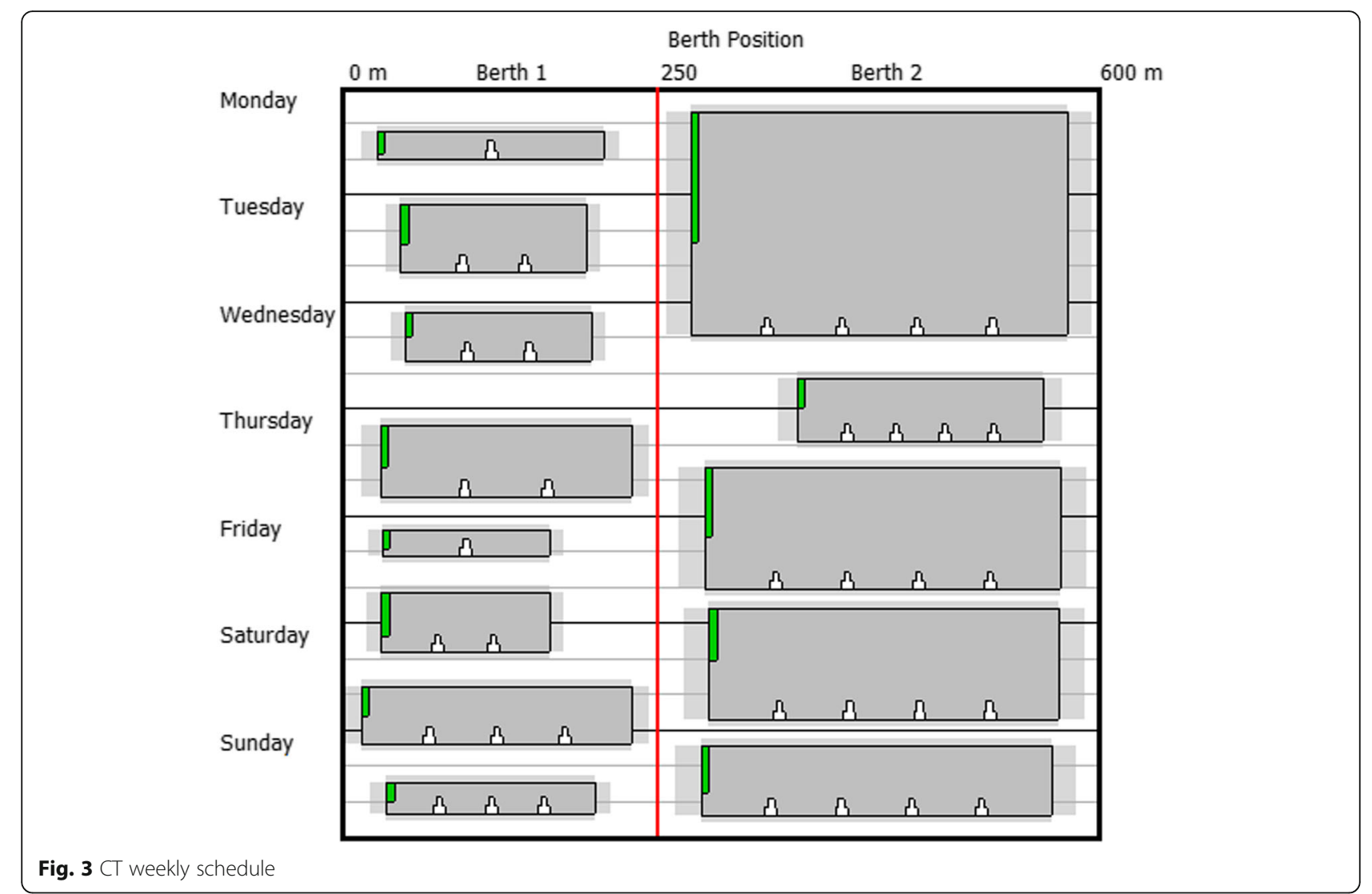

stacking zones; import, export and a zone for empty containers. Every block for full containers is served by an RTG, while a block with empty containers is served by a reach stacker. All the resources of the same type have the same specifications. No replacing of containers has been done at the storage once they have been placed in their final slot.

The terminal's traffic in the basic model consists of thirteen services that cover the following types of ships:

- $46.15 \%$ feeder ships (up to 1500 TEU)

- $23.08 \%$ Panamax ships (1500-5000 TEU)

- $30.77 \%$ Post Panamax ships (over 5000 TEU)

Despite the fact that Post Panamax ships represent only $30.77 \%$ of all ships that arrive at the terminal, they account for $66.20 \%$ of the terminal throughput. The initial annual throughput amounts to 630,000 TEU per year. Simulations were conducted for a period of 1 week or until the completion of the transhipment operations on the last scheduled ship. The ship schedule for every day of the week and the placement at the individual berth is illustrated with grey squares in Fig. 3.

\subsection{Analyses}

The chosen schedule foresaw every day berth occupation for a duration of 1 week (shown in Fig. 3). At the first berth, ships of up to 2300 TEUs and lengths of up to $220 \mathrm{~m}$ called, while the second berth is primarily intended for the larger Post Panamax ships, the length of which is approximately $300 \mathrm{~m}$.

During the analysed week, P QCs handled 3306 TEUs, accounting for $27.25 \%$ of transhipped TEUs, while the remaining three quarters of total weekly throughput were performed by PP QCs. The average occupancy of all QCs in the analysed week was $43.47 \%$, while the average working time of PP QCs reached 62.88\%. A very significant output for the implementation of the assigned manipulations was the QCs waiting time for YTs to arrive. On average all eight QCs accounted for $11.44 \%$ of waiting time, which is not much, but if we focus only on the PP QCs, the waiting time rose to $19.56 \%$, meaning that they required more YTs or faster operations in the yard area. This greatly affects the whole time of the ships in the port as the QC can't drop the container on the surface and move to another manipulation, rather must wait. On the other hand, P QCs accounted for only $3.32 \%$ of waiting time, meaning that five YTs were sufficient for them.

On average, QCs transhipped slightly fewer than 20 moves/hour, which is acceptable for the small QCs and also in line with actual achievements in nearby ports, while such a small achievement for large QCs 
Table 3 Results of the operations at the berth subsystem (three simulation sets) with different number of YTs

\begin{tabular}{|c|c|c|c|c|c|c|c|}
\hline & \multicolumn{2}{|c|}{$\begin{array}{c}\text { Working time } \\
(\%)\end{array}$} & \multicolumn{2}{|c|}{$\begin{array}{l}\text { Waiting time } \\
(\%)\end{array}$} & \multicolumn{2}{|c|}{ Moves/hour } & \multirow[t]{2}{*}{$\begin{array}{c}\text { Berth } \\
\text { occupancy } \\
(\%) \\
\end{array}$} \\
\hline & $\mathbf{P}$ & $\mathbf{P P}$ & $\mathbf{P}$ & PP & $\mathbf{P}$ & PP & \\
\hline \multicolumn{8}{|c|}{ SCENARIO 1} \\
\hline $5 \mathrm{YTs}$ & 24.06 & - 62.88 & - 3.32 & $\bullet 19.56$ & - 19.12 & - 19.80 & $\bullet 63.11$ \\
\hline $10 \mathrm{YTs}$ & - 27.99 & 55.09 & 1.20 & 11.36 & - 22.89 & 23.18 & 55.84 \\
\hline $16 \mathrm{YTs}$ & - 20.83 & - 47.80 & $\bullet 0.60$ & - 5.07 & - 22.10 & - 26.23 & - 51.43 \\
\hline \multicolumn{8}{|c|}{ SCENARIO 2} \\
\hline $5 \mathrm{YTs}$ & 11.65 & - 54.21 & $\bullet 3.51$ & - 14.83 & - 16.05 & - 21.00 & - 49.49 \\
\hline $10 \mathrm{YTs}$ & - 15.34 & 47.07 & 2.10 & 8.54 & 19.98 & 24.04 & - 44.67 \\
\hline $16 \mathrm{YTs}$ & $\begin{array}{l}-7.09 \\
\end{array}$ & - 42.81 & $\bullet 0.03$ & - 3.66 & - 23.22 & - 26.48 & - 42.87 \\
\hline \multicolumn{8}{|c|}{ SCENARIO 3} \\
\hline $5 \mathrm{YTs}$ & 19.53 & - 57.16 & $\cdot 4.65$ & $\bullet 17.03$ & $\bullet 17.65$ & - 19.99 & - 55.04 \\
\hline $10 \mathrm{YTs}$ & - 21.42 & . 46.93 & 2.56 & 7.27 & 20.91 & - 24.73 & 48.34 \\
\hline $16 \mathrm{YTs}$ & $\bullet 14.61$ & - 45.79 & -0.49 & - 5.32 & - 22.86 & - 25.68 & - 41.82 \\
\hline \multicolumn{8}{|c|}{ SCENARIO 4} \\
\hline $5 \mathrm{YTs}$ & $\bullet 35.55$ & - 58.90 & $\bullet 7.22$ & - 17.97 & 18.77 & - 19.77 & - 62.32 \\
\hline $10 \mathrm{YTs}$ & 28.89 & . 53.75 & 6.45 & 0.53 & - 17.90 & - 23.54 & $\circ 55.59$ \\
\hline $16 \mathrm{YTs}$ & $\cdot 21.27$ & - 53.73 & $\bullet 3.55$ & - 10.33 & - 19.65 & 23.53 & - 53.74 \\
\hline \multicolumn{8}{|c|}{ SCENARIO 5} \\
\hline $5 \mathrm{YTs}$ & - 27.65 & - 55.45 & - 4.94 & - 13.57 & - 19.42 & - 21.70 & $\bullet 60.74$ \\
\hline $10 \mathrm{YTs}$ & - 26.56 & 52.46 & 2.90 & 9.37 & 21.05 & - 24.01 & 57.71 \\
\hline $16 \mathrm{YTs}$ & - 26.92 & - 51.35 & $\bullet 1.19$ & - 8.72 & - 22.66 & - 24.41 & - 55.93 \\
\hline \multicolumn{8}{|c|}{ SCENARIO 6} \\
\hline $5 \mathrm{YTs}$ & 29.50 & - 64.51 & $\bullet 7.90$ & 17.68 & - 17.15 & 20.98 & $\bullet 65.56$ \\
\hline $10 \mathrm{YTs}$ & - 27.93 & - 58.61 & - 2.28 & $\cdot 12.72$ & - 21.78 & - 22.79 & -60.82 \\
\hline $16 \mathrm{YTs}$ & $\bullet 34.36$ & - 64.50 & 4.97 & - 19.31 & 20.14 & - 20.61 & $\begin{array}{l}-65.71 \\
\end{array}$ \\
\hline \multicolumn{8}{|c|}{ SCENARIO 7} \\
\hline $5 \mathrm{YTs}$ & 0.00 & 07.17 & 0.00 & 19.93 & 0.00 & - 20.32 & 70.54 \\
\hline $10 \mathrm{YTs}$ & 0.00 & - 67.92 & 0.00 & - 20.90 & 0.00 & 20.46 & - 73.12 \\
\hline $16 \mathrm{YTs}$ & 0.00 & - 59.48 & 0.00 & $\cdot 13.42$ & 0.00 & - 23.02 & $\cdot 64.99$ \\
\hline
\end{tabular}

is unacceptable. This affected the berth occupancy, which amounted to $62.70 \%$. Though, as the maximum limit to still achieve optimal results on the berth is set at $65 \%$, it is still within an acceptable range. Nevertheless, at the second berth where large ships are mooring the actual occupancy $(74.06 \%)$ exceeded the allowed limit. With such results, the optimization of the quay should be considered by the terminal operators.

The simulation has shown that for the current annual traffic the storage area of the terminal is still sufficient or even underutilised. The average utilization of the yard space amounted to $31.21 \%$, while the maximum recommended is up to $60 \%$. The RTGs placed on the import blocks waited much longer for the arrival of YTs than those placed on export blocks. The average utilization rate of the YCs therefore showed that there is currently a surplus of YCs at the terminal. Nevertheless, in case of their reduction higher congestion would occur, as there is a lack of YTs for transporting containers from berth to yard and vice versa to help to achieve optimal results.

With the selected inputs, the working time of the simulated terminal lasted $210.65 \mathrm{~h}$. If we would consider only the berth subsystem in the simulation (excluding all the yard operations), that time would be reduced to 140 $\mathrm{h}$, as QCs would achieve higher productivity. The simulation showed that in our case the biggest problem is in the transfer area where YTs are operating.

\subsection{Simulations}

The results of the basic model showed that the insufficient number of YTs were the principal cause for poorer efficiency of QCs and longer ship stops at the terminal. For that reason, further simulations were conducted by increasing the number of the YT. 


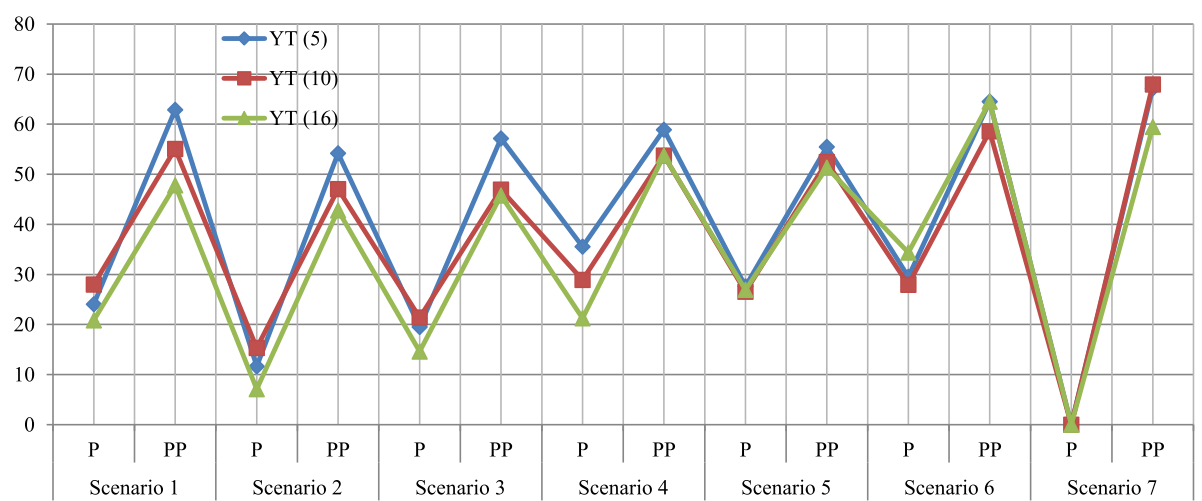

Fig. 4 QCs working time (\%)

Initially, we increased the transfer mechanization by one on every QC, but relevant results were not reached until we allocated ten YTs to every QC. The most suitable results (comparable to that achieved in ports) were obtained only by placing sixteen YTs on a QC. Even though that is not common in small size terminals it allowed us to obtain the desired productivity of the QCs when yard productivity was not at its highest.

Further simulations were therefore divided into the following three sets:

- Set 1: each QC served by 5 YTs,

- Set 2: each QC served by 10 YTs,

- Set 3: each QC served by 16 YTs.

Thus it was possible to determine how a change in the number of YTs affected the productivity of QCs and ship serving times.

In each of the three sets, the same simulations were effectuated covering seven scenarios where container throughput gradually rose to near 1 million TEUs. At the same time, berth and storage capacities were optimized in order to enable the reception of such traffic. The scenarios are described in Table 2.
Due to the use of probability distribution different simulation runs of the same scenario did not give us identical results. Consequently, several simulation runs were performed for each scenario. The reported results are the average of the simulation runs of each scenario.

\section{Results}

The simulations included the comparison of each scenario with different criteria and with different numbers of YTs. The results are shown in Table 3 and in Fig. 4 to Fig. 9. The best obtained results are marked with a green dot, while the worst have red dots. The yellow dot denotes cases where the obtained results were not much different from the best one and were therefore also very favourable.

The study included P and PP QCs, as this is the equipment of most medium and small ports which are included in both feeder and deep sea services. Primarily, the simulations were focused on the berth subsystem, as that area in connection with the transfer mechanization was identified as the one affecting most the time of the ships in port.

The results in all scenarios showed that when the number of YTs per QC had been increased to the maximum, the working time of $\mathrm{QCs}$ and the $\mathrm{QC}$ waiting time for YTs to come decreased (Figs. 4, 5).

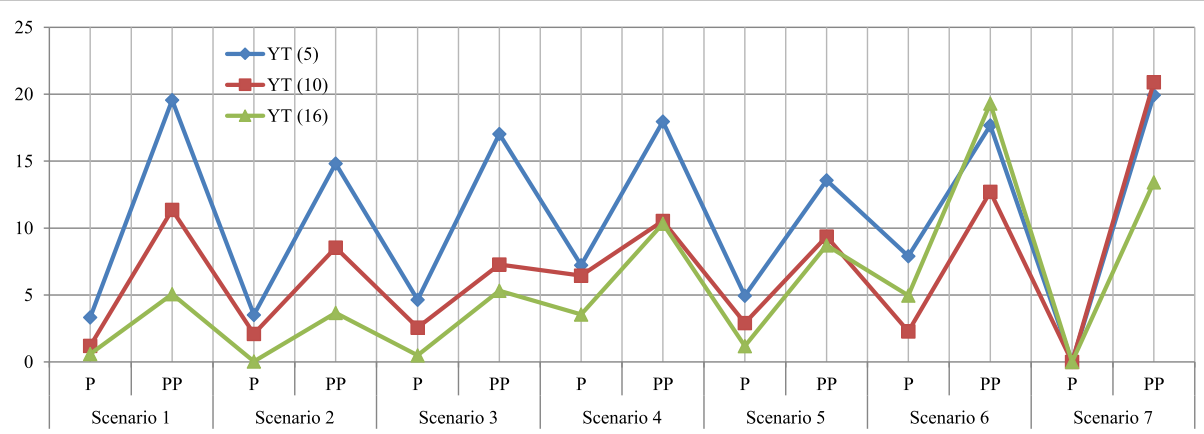

Fig. 5 QCs waiting time (\%) 


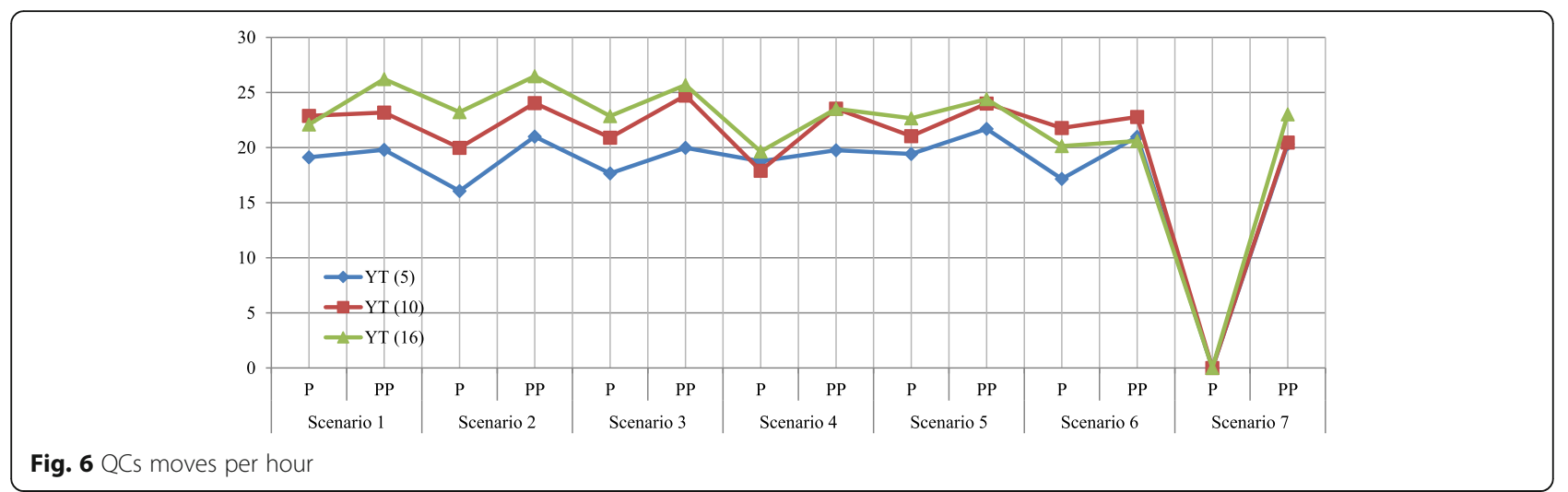

This has had a positive effect on the QC productivity and on the reduction of the berth occupancy ratio, which is crucial if the port wants to increase annual traffic, acquire larger ships and assure them fast operations (Figs. 6, 7). The exception was scenario 6, where the best results in all criteria were achieved by increasing the number of YTs to 10 (Figs. 4, 5, 6 and 7). It is also clearly shown that in scenarios 3, 4 and 5 PP QCs achieved very favourable results with 10 YTs on each QC (Figs. 4, 5, and 6). Those are significantly similar to the results of the 3rd set of simulations, which indicates that 10 YTs would be sufficient to achieve good transhipment effects on ships in case of traffic increase to $689,000 \mathrm{TEU}$ or more. In almost all scenarios the 3rd set of simulations provided the lowest berth occupancy rates (Fig. 7). Nevertheless, in the 2nd set very favourable results that did not exceed the recommended critical point of $65 \%$ were achieved (Fig. 7), which means that a financial investment in 16 YTs would not make sense. In addition, under such conditions, storage problems would be exacerbated. They were significantly worse with 16 YTs than with 10 YTs on a QC (Figs. 8, 9). After numerous simulations, it was clear that the best results on the yard were achieved in the 1st set of simulations with 5 YTs on each QC (Figs. 8, 9). We are therefore dealing with an extremely complex problem that requires important decisions. For ports it is essential to determine the point of balance, where the berth productivity required by the ship-owners can be achieved with the least negative effects on the storage operations. Storage problems decrease the efficiency of the berth subsystem, that is why ports cannot ignore berth requirements and choose the number of YTs that corresponds primarily to the yard.

The survey showed that with a terminal of such dimensions it is possible to achieve optimum results while reaching a throughput of 850,000 TEU. With a million TEU the productivity is significantly reduced, and the overall system becomes overloaded. A graphic overview of the changes in the results obtained during stage simulations are emphasised in the following Figures.

\section{Discussion and conclusion}

The article presents the results of a study conducted on a hypothetical small CT using Flexsim CT 3.3 software. The analysis covered all berth-yard-berth operations with the emphasis on the correct allocation of transfer mechanization to allow the optimal functioning of the berth, and, consequently, a faster turnaround of the ship in the port. As nowadays ship-owners are utilizing ever larger ships even in smaller ports, such ports are faced with increasing amounts of containers and requirements

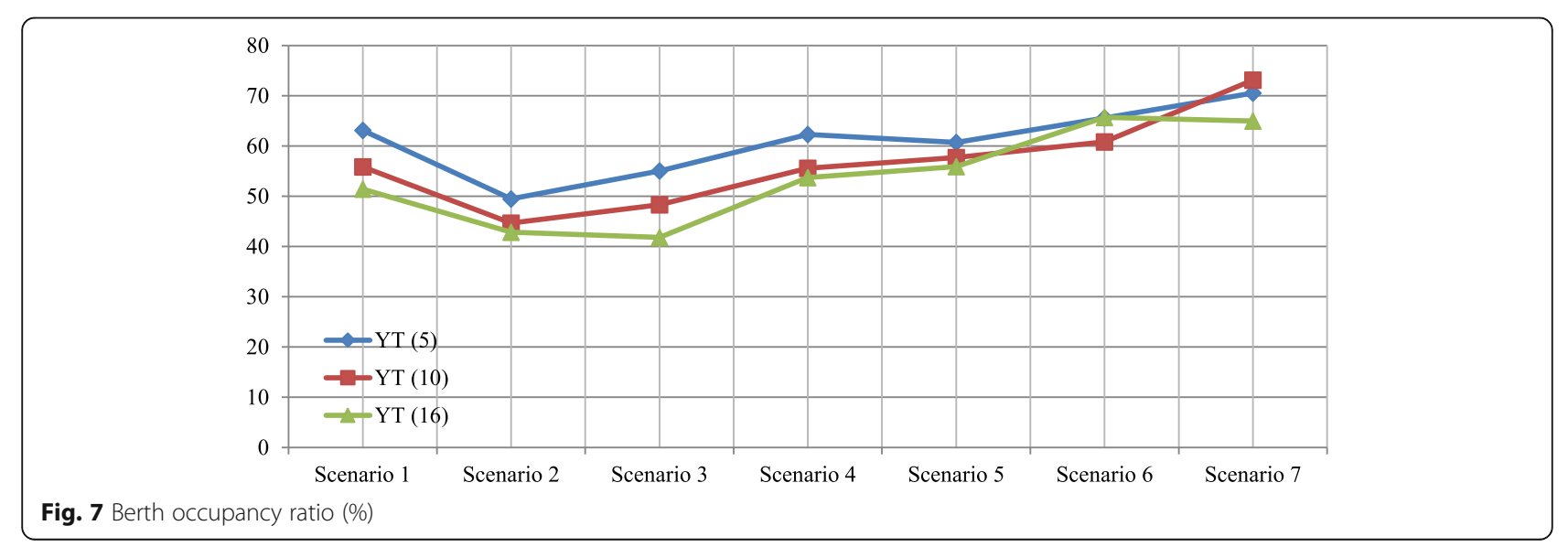




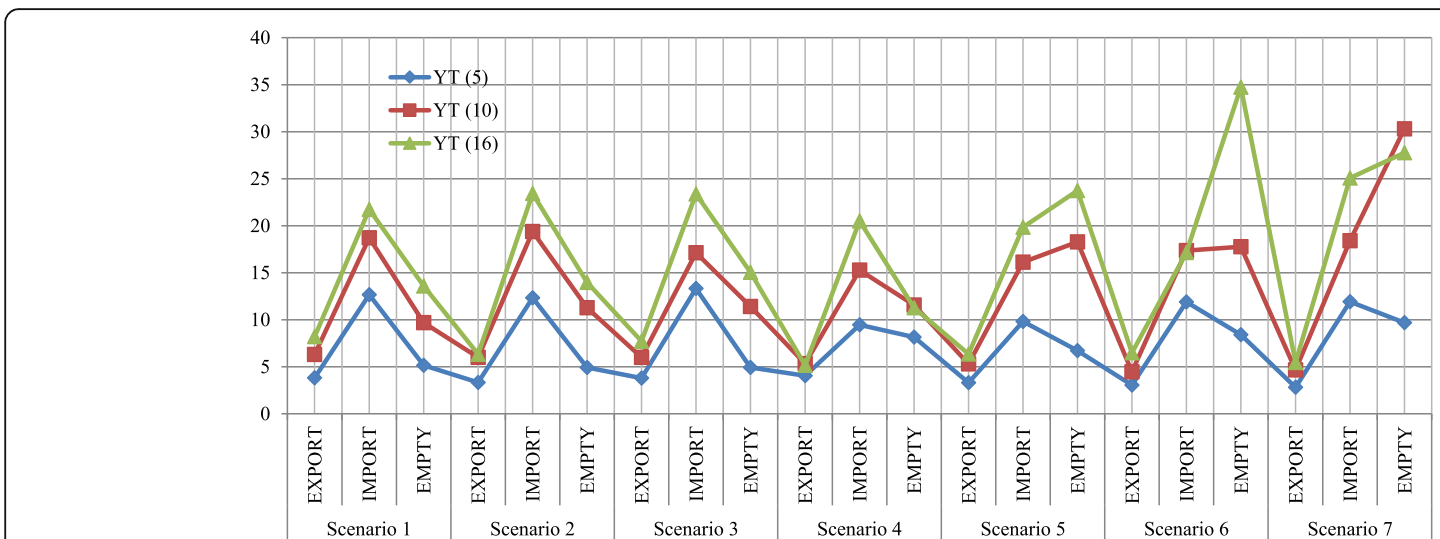

Fig. 8 YCs waiting time ( $\mathrm{min}$ )

for faster ship operations in order to reduce costs in ports.

We based our study on the work of Gamal Abd ElNasser A. Said and El-Horbaty [27], in which a 54\% reduction in container turnaround time at the port was achieved by applying the optimization model for storage space allocation at the Alexandria container terminal. In our case, we used the data of a hypothetical terminal with the capacity of 630,000 TEU and the simulations were divided into seven scenarios that allowed a gradual increase in traffic up to about one million TEU. The simulations were run in three sets, each using a different number of YTs per QC.

The results showed that, on average, the QCs in all seven scenarios achieved the most favourable results with 16 YTs, but the simulation set with 10 YTs serving a single QC is not significantly different. Therefore, the investment in 16 YTs per QC (according to the results obtained) is not worthwhile, and without an exceptionally good strategy for allocating operations to YTs, congestion would occur on both subsystems considered. However, the situation was reversed in the yard area. Therefore, in our case, increasing the number of internal transfer mechanization has a negative impact on the operation in the yard area. Regardless, due to the poor results obtained at the berth with 5 YTs on one QC, the number of YTs had to be increased, even with the risk of a slight deterioration of the productivity in the storage area. Our aim was to achieve a QC productivity and berth occupancy that meets the requirements that ship-owners have today in smaller ports. This is why we opted for the higher number of YTs per crane. In addition, choosing the wrong strategy for assembly can lead to congestion in the berth area - especially in the storage area - which in turn has a negative impact on operations at the quay.

In summary, the competitiveness and operating level of CTs currently depends on the global demand for

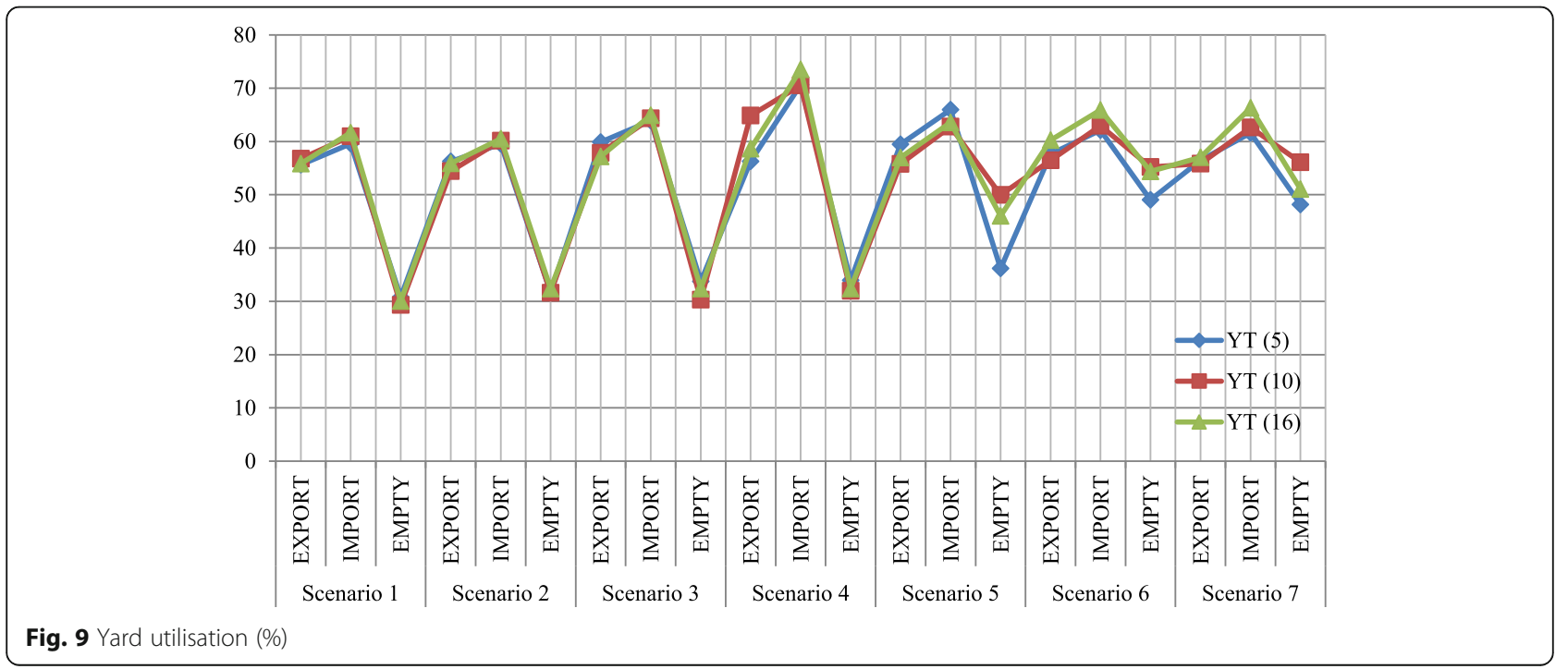


container transport and, consequently, on the decisions of ship-owners to use larger vessels. In this context, medium and small ports are in a very difficult position as they are subject to a cascade effect, which according to Merk et al. [25] means that ships that have become redundant due to very large new vessels are used in direct services that include medium and small ports. The results of this study are important for operators of smaller CTs as they can use this model to find the right number of handling mechanizations to increase annual throughput. The main limitation stems from the fact that not all CTs were included in the analysis, but only one smaller terminal. Therefore, the conclusions presented here are limited to providing an answer to the main question of how to ensure fast and efficient handling of ships that now reach 6000 to 8000 TEU and how to meet the main demand of ship-owners - fast handling at ports to reduce costs. The focus was on performance metrics and operating times, which depend on mechanisation in each subsystem. Since the results of the 2nd set of simulations gave quite good results for both subsystems in scenarios with increased annual traffic, it would be most beneficial for a small container port to choose 10 YTs per individual QC.

The potential of many models is limited by data availability. The lack of detailed data remains a major challenge, also for determining the right number of YT to QC to ensure better productivity in the berth and yard subsystems. However, the evaluated results show that the presented concept would lead to a significant improvement in the overall productivity of the small CT. The results obtained proved to be authentic; however, we are wondering whether a terminal of such capacities can achieve even better results in both subsystems using alternative transfer mechanization. Our further research will thus focus on upgrading the presented model, where transfer operations will be accomplished by another type of transfer mechanization. In that way it will be possible to compare the results and create some good guidelines for efficient optimization of operation in small container ports.

\section{Acknowledgements}

'Not applicable' for that section.

\begin{abstract}
Authors' contributions
As a leading author and the main contributor MS has built the hypothetical container terminal in the computer software and effectuated the simulations She has also analyzed and interpreted the obtained results and was a major contributor in writing the manuscript. ET as a coauthor has analyzed the area background, helped to obtain the data from selected ports and helped to develop the simulation methodology. The authors read and approved the final manuscript.
\end{abstract}

\section{Funding}

'Not applicable' for that section.
Availability of data and materials

All data generated or analysed during this study are included in this published article.

\section{Declarations}

\section{Competing interests}

The authors declare that they have no competing interests.

Received: 19 June 2019 Accepted: 16 February 2021

Published online: 22 March 2021

\section{References}

1. Bartošek, A., \& Marek, O. (2013). Quay cranes in container terminals. Transactions on Transport Sciences, 6(1), 9-18. https://doi.org/10.2478/v101 58-012-0027-y.

2. Beškovnik, B., Twrdy, E., \& Bauk, S. (2019). Developing higher berth productivity: Comparison of eastern adriatic container terminals. Promet Traffic \& Transportation, 31(4), 397-405.

3. Bierwirth, C., \& Meisel, F. (2010). A survey of berth allocation and quay crane scheduling problems in container terminals. European Journal of Operational Research, 202(3), 615-627. https://doi.org/10.1016/j.ejor.2009.05.031.

4. Bierwirth, C., \& Meisel, F. (2015). A follow-up survey of berth allocation and quay crane scheduling problems in container terminals. European Journal of Operational Research, 244(3), 675-689. https://doi.org/10.1016/..ejor.2014.12. 030.

5. Böse, J. W. (2011). In J. W. Böse (Ed.), Handbook of terminal planning, (vol. 49). Springer Science+Business Media.

6. Brinkmann, B. (2011). Operations system of container terminals: A compendious overview. In J. W. Bose (Ed.), Handbook of terminal planning, (pp. 25-39). Springer and Springer Science+Business Media, LLC.

7. Carlo, H. J., Vis, I. F. A., \& Roodbergen, K. J. (2014a). Storage yard operations in container terminals: Literature overview, trends, and research directions. European Journal of Operational Research, 235(2), 412-430. https://doi.org/1 0.1016/j.ejor.2013.10.054

8. Carlo, H. J., Vis, I. F. A., \& Roodbergen, K. J. (2014b). Transport operations in container terminals: Literature overview, trends, research directions and classification scheme. European Journal of Operational Research, 236(1), 1-13. https://doi.org/10.1016/j.ejor.2013.11.023.

9. Dragović, B., Tzannatos, E., \& Park, N. K. (2017). Simulation modelling in ports and container terminals: Literature overview and analysis by research field, application area and tool. Flexible Services and Manufacturing Journal, 29(1), 4-34. https://doi.org/10.1007/s10696-016-9239-5.

10. Gharehgozli, A. H., Vernooij, F. G., \& Zaerpour, N. (2017). A simulation study of the performance of twin automated stacking cranes at a seaport container terminal. European Journal of Operational Research, 261(1), 108128. https://doi.org/10.1016/j.ejor.2017.01.037.

11. Giallombardo, G., Moccia, L., Salani, M., \& Vacca, I. (2010). Modeling and solving the tactical berth allocation problem. Transportation Research Part B: Methodological, 44(2), 232-245. https://doi.org/10.1016/j.trb.2009.07.003.

12. Goodchild, A. V., \& Daganzo, C. F. (2006). Double-cycling strategies for container ships and their effect on ship loading and unloading operations. Transportation Science, 40(4), 473-483. https://doi.org/10.1287/trsc.1060.0148.

13. Gupta, A., Roy, D., de Koster, R., \& Parhi, S. (2017). Optimal stack layout in a sea container terminal with automated lifting vehicles. International Journal of Production Research, 55(13), 3747-3765. https://doi.org/10.1080/002 07543.2016.1273561

14. He, J., Chang, D., Mi, W., \& Yan, W. (2010). A hybrid parallel genetic algorithm for yard crane scheduling. Transportation Research Part E: Logistics and Transportation Review, 46(1), 136-155. https://doi.org/10.1016/j.tre.2009. 07.002.

15. Hervás-Peralta, M., Poveda-Reyes, S., Molero, G. D., Santarremigia, F. E., \& Pastor-Ferrando, J.P. (2019). Improving the performance of dry and maritime ports by increasing knowledge about the Most relevant functionalities of the terminal operating system (TOS). Sustainability, 1648(6). https://doi.org/10.3390/su11061648.

16. Hinkka, V., Porkka, J., Fatima, Z., Hyvärinen, J., Huovila, A., Morales-Fusco, P., . Soley, G. (2018). Terminal planning: The selection of relevant KPIs to evaluate operations. Paper presented at the Transport Research Arena TRA 2018. 
17. Huynh, N., \& Walton, C. M. (2011). Improving efficiency of drayage operations at seaport container terminals through the use of an appointment system. In J. W. Bose (Ed.), Handbook of terminal planning, (pp. 323-343). Springer and Springer Science+Business Media, LLC.

18. Imai, A., Sun, X., Nishimura, E., \& Papadimitriou, S. (2005). Berth allocation in a container port: Using a continuous location space approach. Transportation Research Part B: Methodological, 39(3), 199-221. https://doi. org/10.1016/j.trb.2004.04.004.

19. Kim, K.-H., \& Günther, H.-O. (2006). Container terminals and terminal operations. OR Spectrum, 28(4), 437-445. https://doi.org/10.1007/s00291-0060059-y.

20. Kotachi, M., Rabadi, G., \& Obeid, M. F. (2013). Simulation modeling and analysis of complex port operations with multimodal transportation. Procedia Computer Science, 20, 229-234. https://doi.org/10.1016/j.procs.2013. 09.266.

21. Kourounioti, I., Polydoropoulou, A., \& Tsiklidis, C. (2016). Development of models predicting dwell time of import Containers in Port Container Terminals - An artificial neural networks application. Transportation Research Procedia, 14, 243-252. https://doi.org/10.1016/j.trpro.2016.05.061.

22. Kress, D., Meiswinkel, S., \& Pesch, E. (2019). Straddle carrier routing at seaport container terminals in the presence of short term quay crane buffer areas. European Journal of Operational Research, 279(3), 732-750. https://doi.org/1 0.1016/j.ejor.2019.06.028.

23. Liang, C., Hwang, H., \& Gen, M. (2011). A berth allocation planning problem with direct transshipment consideration. Journal of Intelligent Manufacturing 23(6), 2207-2214. https://doi.org/10.1007/s10845-011-0566-9.

24. Meisel, F. (2009). Seaside operations planning in container terminals. PhysicaVerlag A Springer Company. https://doi.org/10.1007/978-3-7908-2191-8.

25. Merk, O., Busquet, B., \& Aronietis, R. (2015). The impact of mega-ships Retrieved from http://www.oecd-ilibrary.org/transport/the-impact-of-megaships_5jlwvzcm3j9v-en.

26. Sacone, S., \& Siri, S. (2009). An integrated simulation-optimization framework for the operational planning of seaport container terminals. Mathematical and Computer Modelling of Dynamical Systems, 15(3), 275-293. https://doi. org/10.1080/13873950902808636.

27. Said, G. A. E.-N. A., \& El-Horbaty, E.-S. M. (2015). A simulation modeling approach for optimization of storage space allocation in container terminal. Information, Systems and Control Engineering, 9(1), 168-173.

28. Said, G. A. E.-N. A., Mahmoud, A. M., \& El-Horbaty, E.-S. M. (2014). Solving container terminals problems using computer-based modeling. International Journal of Computer Science and Engineering (IJCSE), 3(3), 91-100. https://a rxiv.org/abs/1407.6384.

29. Seyedalizadeh Ganji, S. R., Babazadeh, A., \& Arabshahi, N. (2010). Analysis of the continuous berth allocation problem in container ports using a genetic algorithm. Journal of Marine Science and Technology, 15(4), 408-416. https:// doi.org/10.1007/s00773-010-0095-9.

30. Singgih, I. K., Jin, X., Hong, S., \& Kim, K. H. (2016). Architectural Design of Terminal Operating System for a container terminal based on a new concept. Industrial Engineering and Management Systems, 15(3), 278-288. https://doi.org/10.7232/iems.2016.15.3.278.

31. Sislioglu, M., Celik, M., \& Ozkaynak, S. (2018). A simulation model proposal to improve the productivity of container terminal operations through investment alternatives. Maritime Policy \& Management, 46(2), 156-177. https://doi.org/10.1080/03088839.2018.1481544.

32. Stahlbock, R., \& Voß, S. (2008). Operations research at container terminals: A literature update. OR Spectrum, 30(1), 1-52. https://doi.org/10.1007/s00291007-0100-9.

33. Steenken, D., Voß, S., \& Stahlbock, R. (2004). Container terminal operation and operations research - a classification and literature review. OR Spectrum, 26(1), 3-49. https://doi.org/10.1007/s00291-003-0157-z.

34. Stojaković, M., \& Twrdy, E. (2016). A decision support tool for container terminal optimization within the berth subsystem. Transport, 31(1), 29-40. https://doi.org/10.3846/16484142.2014.994226.

35. Stojaković, M., \& Twrdy, E. (2019). The influence of yard trucks on berth operations in smaller container terminals. Scientific Journal of Maritime Research, 33, 171-175. https://doi.org/10.31217/p.33.2.6.

36. Tang, G., Qin, M., Zhao, Z., Yu, J., \& Shen, C. (2020). Performance of peak shaving policies for quay cranes at container terminals with double cycling. Simulation Modelling Practice and Theory, 104, 102129. https://doi.org/10.101 6/j.simpat.2020.102129.
37. Vis, I. F. A., \& De Koster, R. (2003). Transshipment of containers at a container terminal: An overview. European Journal of Operational Research, 147(1), 116. https://doi.org/10.1016/S0377-2217(02)00293-X.

38. Woo, Y. J., \& Kim, K. H. (2011). Estimating the space requirement for outbound container inventories in port container terminals. International Journal of Production Economics, 133(1), 293-301. https://doi.org/10.1016/j. ijpe.2010.04.032

39. Yang, Z., Li, C., \& Zhao, Q. (2018). Dynamic time estimation based AGV dispatching algorithm in automated container terminals. Paper presented at the Chinese Control Conference (CCC).

40. Zhang, C., Liu, J., Wan, Y.-W., Murty, K. G., \& Linn, R. J. (2003). Storage space allocation in container terminals. Transportation Research Part B: Methodological, 37(10), 883-903. https://doi.org/10.1016/s0191-2615(02 )00089-9.

41. Zhang, H., \& Kim, K. H. (2009). Maximizing the number of dual-cycle operations of quay cranes in container terminals. Computers and Industrial Engineering, 56(3), 979-992. https://doi.org/10.1016/j.cie.2008.09.008.

42. Zhao, W., \& Goodchild, A. V. (2013). Using the truck appointment system to improve yard efficiency in container terminals. Maritime Economics \& Logistics, 15(1), 101-119. https://doi.org/10.1057/mel.2012.23.

\section{Publisher's Note}

Springer Nature remains neutral with regard to jurisdictional claims in published maps and institutional affiliations.

\section{Submit your manuscript to a SpringerOpen ${ }^{\circ}$ journal and benefit from:}

- Convenient online submission

- Rigorous peer review

- Open access: articles freely available online

High visibility within the field

- Retaining the copyright to your article

Submit your next manuscript at $\boldsymbol{\nabla}$ springeropen.com 